\title{
Evolution and developmental biology in The Netherlands
}

\author{
Frederick R. Schram \\ Institute for Biodiversity and Ėcosystem Dynamics, University of Amsterdam, Mauritskade 57, 1092 AD \\ Amsterdam, The Netherlands
}

\section{A short history}

I have long maintained that in the unfolding of exciting lines of research, seldom can one plan how to achieve a cooperative program. "Planned science," more often than not, is forced science and not particularly productive. Far more significant is the role of serendipity in defining an exciting and innovative line of research, i.e., a truly stimulating cooperation. Fundamental advances simply cannot be planned for; one has to flow with the current.

Thus it was that serendipity brought together the research group in Experimental Embryology of Prof. dr. J.A.M. van den Biggelaar at the University of Utrecht, and my own group in Systematics and Zoogeography at the University of Amsterdam. Several years ago I had received a grant proposal to review from the Dutch science research council (NWO). The proposed project intended to examine patterns of early development in the gastropod Patella in a large scale, evolutionary context. I found the project an exciting one and gave it my highest endorsement. Furthermore, so taken was I by the proposal that I made contact with its author, Prof. van den Biggelaar. I had long entertained the idea that a combination of an evolutionarily inclined group in embryology with embryologically sensitive systematists could achieve great things. I revealed myself to Jo van den Biggelaar as one of his reviewers and proposed that we meet.

Prof. van den Biggelaar and I discovered we indeed had much in common. After some exchanges of visits and further discussions over several months we decided we had a solid basis for cooperation. I had published one of the first computer generated cladograms of all the animal phyla and had a vital interest in the phylogeny of metazoans. Prof. van den Biggelaar had been working for years to define the parameters of early development and differentiation in protostomes, especially with Patella vulgata as a model system. At that time, sorting out the relationships of major taxa at the base of the protostome clade was (and still is) an intense field of research and speculation, so we believed we had the basis for an innovative approach to the subject. We prepared a grant proposal to NWO.

Funny things happen on the way to innovation it is necessary that one not charge too far out in front of the pack, otherwise potential reviewers will not recognize what you are up to. We prepared our first proposal in early 1996 . We constructed a threepronged research effort with a combination of three sub-projects with Prof. van den Biggelaar as program coordinator. We were confident we would succeed in attracting funds. When the reviews came in, our hopes began to wane. More than half the reviewers were from the field of developmental biology, and they were almost uniformly opposed to "wasting" money on such a "risky" venture. Slightly less than half of the reviewers were systematists, but they were quite positive in their evaluations. The negatives weighed in the final board decision to not fund the program.

- I then tried to at least get the phylogenetics side of the program up and running, and prepared another NWO proposal - it finished just short of the 
cut-off point for funding. We then prepared another program proposal the following year, "A Novel key to Solving Animal Phylogeny: a Fusion of Developmental Biology and Cladistics," in which we readjusted the work scheme to accommodate one Ph.D. student in Amsterdam and 2 post-docs in Utrecht, and placed me as the program coordinator. This time, most of the reviewers were from the systematics side and all quite positive, the few developmental biologists were not so negative, and the program carried the board at NWO.

I recount the history here in some detail to illustrate a point. What we believed would be an innovative, cutting edge wedding of systematics and developmental genetics in 1995 was, by the time it was finally up and operating in 1998, only "running with the pack" - so fast moving is the field of evo-devo. Funding truly innovative research often requires that someone in a funding agency somewhere makes a leap of faith that frees them from the tyranny of constraint that all too often formal review processes engender.

The cooperating research team consisted of several people. Besides Jo van den Biggelaar and myself we had in Utrecht Wim Dictus, André van Loon, and René Dohmen to carry the experimental embryology research. In Amsterdam, my colleague Ronald Sluys had a long established interest in flatworms in which early development was one of his focuses. We had the good fortune to secure the services in that first year of two outstanding people. Peter Damen, a former Ph.D. student from the van den Biggelaar lab, took up the post-doc in Utrecht, "Cell lineage and specification of developmental fate and mesoderm differentiation in Patella." Ronald Jenner, a graduate of Utrecht, who took up the Ph.D. training position in Amsterdam, worked on "Morphological and developmental aspects of the phylogeny of animal phyla." In addition to these two people, three Ph.D. students in Utrecht funded from outside the formal NWO program joined the team. Lex Nederbragt, who had taken the position attached to the grant I had reviewed a few years earlier, worked on "The evolution of developmental programs: a case study on the gastropod mollusc Patella vulgata." Pascal te Welscher, who had a Ph.D. project funded out of Utrecht faculty funds, began work on "The orthodenticle and orthopedia genes of Patella vulgata and the development of ciliary bands, stomodeum, apical organ, and nervous system." Another Ph.D. student out of the United States, Eric Edsinger-Gonzales, entered the group with a project focused on "Early development and differentiation in polychaetes." In addition to on-going informal contacts between members of the team, we planned to schedule formal gatherings at least 3 times a year wherein we would all come together for a day and review progress to that point. On the first anniversary of the program in the Spring of 1999, we brought in Prof. Mark Martindale from the University of Hawaii to deliver some lectures and provide an outside review of our first year's progress. Later in the program, post-doc funds from the faculty in Amsterdam allowed me to add Stefan Koenemann into our team to help me carry on with application of $H o x$ and other developmental gene pattern expression to assessing homologies within arthropods.

The original plans changed, of course, as such things are prone to do. For various reasons, the planned for second post-doc in Utrecht, to take up the project "Protostomian animals - an evolutionary developmental perspective," did not work out. This was a critical project that was to look at early spiral cleavage patterns in a variety of lower protostomes. The Ph.D. project on orthodenticle and orthopedia in molluscs eventually combined into Lex Nederbragt's research. Nevertheless, our program carried on with the other projects. Peter Damen in the end produced a remarkable series of studies that mapped in detail the cell lineages in Patella from the spirally cleaving early embryos through to the differentiation of various mesodermal tissues in the trochophore larva. Lex Nederbragt determined the role of twist and snail in early development in Patella and salvaged much of the results from the orthodenticle and orthopedia research, defending his $\mathrm{Ph}$.D. dissertation on 4 February, 2002. Ronald Jenner went on to produce a significant set of papers evaluating methodological issues applicable to future analyses of metazoan phylogeny and defended his Ph.D. cum laude on 17 April, 2002. And with Stefan Koenemann's help a series of papers on developmental genetics and arthropod evolution are appearing.

It is because of these achievements that we chose 
to celebrate the end of our program with an international symposium on evolution and development, "Metazoan Deep History: evaluating hypotheses about macroevolution of animal body plans." This was held on 16 April, 2002 in connection with the $\mathrm{Ph} . \mathrm{D}$. defense the following day of Ronald Jenner.

\section{The papers herein}

The paper on "Cleavage, gastrulation, and germ disc formation of the amphipod Orchestia cavimanna (Crustacea, Malacostraca, Peracarida)" by Gerhard Scholtz and Carsten Wolff demonstrates that not all types of determinate cleavage within protostomes are necessarily spiral. While spiral determinate cleavage is the classic, oft-stated, great autapomorphy of the protostome metazoans, it is often overlooked that other forms of cleavage exist among these animals. For example, spiral duet cleavage is a hallmark of acoel flatworms, and this process is indeed sometimes cited as evidence for the separate status of the acoels from the regular Platyhelminthes. And a determinate quartet cleavage that ranges from holoblastic to quite superficial is seen in a variety of arthropods and molluscs. The case documented here seems to be unique to amphipods. The pattern of cleavage shifts from one of initially totally dividing cells to one where the expulsion of yolk into a central position in the embryo occurs along with formation of a superficial germ band of cytoplasm. Nevertheless, the use of florescent dyes reveals that clear cell lineages exist in amphipods. Though this has been informally known for some time, Scholtz and Wolff document this here for the first time. It also suggests that it would be profitable to re-examine the purported spiral cleavages that have been noted among the cirripedes and pycnogonids.

An interesting review, "The improbability of dorsal-ventral axis inversion during animal evolution, as presumed by Geoffroy Saint Hilaire," by Jo van den Biggelaar, Eric Edsinger-Gonzales, and myself is an example that illustrates the importance of looking in detail at the study of real animals. The issue of axis inversion between protostomes and deuterostomes originated in the early 1800 's with the writings of Etienne Geoffroy Saint Hilaire, and has been resurrected in recent years by some researchers based on apparently anomalous dorsoventral patterns of expression in developmental genes. However, it is our contention that if Geoffroy Saint Hilaire had known more about comparative embryology, he would never have come up with the idea of axis inversion. In the same vein, if modern molecular geneticists knew more about comparative embryology, their discovery of the conservation of pattern forming genes in vertebrates as well as invertebrates would not have lead to a revival of dorso-ventral axis inversion. It is not that we have the direct exchange of dorsal and ventral surfaces between protostomes and deuterostomes. Rather, there is a complex series of cell migrations that occur during the embryogenesis of protostomes that accounts for the shift of originally dorsal cells to a postero-ventral position, and concomitant migration of the posteriorly oriented blastopore to an antero-ventral location. The evolution of protostomes is a lot more complicated than text-book knowledge would lead us to believe.

Peter Damen and Wim Dictus present part of their results on cell lineage studies, "Newly-discovered muscle in the larva of Patella (Mullusca, Gastropoda) suggests the presence of a larval extensor." This paper emphasizes again that careful embryological and anatomical work is still capable of discovering entirely new things. All one has to be is observant, In this case, the extension and retraction of larval bodies out of their shells are processes that everyone implicitly understood had to be under control of antagonistic muscles. However, until Damen and Dictus' work, we had no proof of this, nor any clear understanding of how these movements occurred. The paper is an object lesson to students who often wonder if there is anything new to be discovered in science.

Stefan Koenemann and I with the paper, "The limitations of ontogenetic data in phylogenetic analyses," take inspiration from the work of the research group at Leiden University under the direction of Prof. dr. Michael Ríchardson. It has long been a dictum of comparative biology that developmental data is important towards understanding the evolution of organisms. Indeed, Haeckel's Biogenic Law, 'ontogeny recapitulates phylogeny,' appeared soon after Darwin's The Origin of Species. More 
recently, Gould's most effective book, Ontogeny and Phylogeny, reintroduced considerations of heterochronic processes in evolutionary studies. Yet, while direct application of data on heterochrony, especially for vertebrates, often gives phylogenetic trees not unlike those drawn from either molecular or adult anatomical features, data from other groups seems to be less effective. We conclude that this is due to the lack of an effective analytical algorithm to handle such data. Ordinary cladistic programs, such as PAUP, are essentially interpretations of data derived from 3-dimensional forms, but these programs are not particularly effective in handling 4dimensional constructs, i.e., data that includes a time element derived from consideration of sequences of ontogenetic stages. Thus, the change noted in anatomy through ontogenetic time is ill handled by such methods.

Ronald Jenner again takes a look at methodological and epistemological issues in cladistic analysis of animal phylogeny, "Boolean logic and character state identity: pitfalls of character coding in metazoan cladistics." The most common scoring of characters involves simple absence/presence determinations. However, this procedure has several problems. Chief of these is that the so-called "plesiomorphic absence" often entails several undefined alternative states. For example, the issue of spiral determinate cleavage [absent or present] is an excellent example. The traditional opposition to this state is posed to be radial indeterminate cleavage. However, as already noted, other possibilities exist. The scoring of an undefined absence thus masks a tremendous amount of truly significant information in sorting out the phylogeny of animals, and it suggests unique homology of unrelated and dissimilar morphologies. Indeed, this and other papers by Jenner have given us insight as to why we have such a forest of cladograms for the Metazoa and little consensus as to the phylogeny of the animal kingdom.

We might conclude with all the above that only molecules afford us the best opportunity to discern the lines of metazoan evolution. However, least we become too complacent, Maximilian Telford, provides a lesson on the limits of even those kinds of data, "Cladistic analysis of molecular characters: the good, the bad, the ugly." Essentially, all the often recognized difficulties of morphological data placed in a cladistic matrix have their correspondences on the molecular side. This is not to state that nothing is sacred. It merely means that we need to abandon the obsession we have with finding absolute truth when we undertake analyses of metazoan, indeed any, phylogeny. We have to always keep in mind that all data is relative and is imbued with varying levels of subjectivity. In other words, we need to treat all data equally with more respect.

Frietson Galis and Barry Sinervo take up "Divergence and convergence in early embryonic stages of metazoans." This subject is really a critical issue when trying to combine systematic analyses with the results of developmental gene research. So often we read in the literature about conserved genes or functions. Galis and Sinervo ask when are these phenomena due to true conservation, i.e., homologies, and when are they merely homoplasies? Even then, it is sometimes difficult to sort out functional considerations from true genealogical matters. Care must be taken in pushing scenarios of evolution derived from developmental studies without framing discussions in a properly cast phylogenetic understanding.

Prof. van den Biggelaar and I had originally thought in the mid-1990s that we had an easy set of goals to achieve: sorting out the early ontogeny and evolution of protostomes, and set a master tree for metazoan phylogenetic relationships. Now we find that as our particular cooperative research program comes to an end, our goals are even more elusive than when we originally started out. Nevertheless, the work goes on.

\section{Publications of the Dutch National Program in evolution and development}

Here then is the total list of publications that resulted from the NWO program, "A Novel key to Solving Animal Phylogeny: a Fusion of Developmental Bíology and Cladistics," grant number 80533-430.

Damen P, Dictus WJAG. 2002. Newly-discovered muscle in the larva of Patella (Gastropoda, Mollusca) suggests the presence of a larval extensor. Contrib. Zool. 71: 37-45. 
Damen P, Dictus WJAG. submitted. New muscle in the larva of Patella (Mollusca, Gastropoda): antagonist of the larval retractor? J. Morph.

Damen P, Dictus WJAG. submitted. Origin of mesoderm in the molluse Patella. Dev, Biol.

Damen P, Dictus WJAG. submitted. Monoclonal and polyclonal origin of the musculature of Patella (Gastropoda): implications for studying evolutionary relations. Amer. Malacol, Bull.

Damen P, Dietus WJAG. in prep . Clonal restriction map of the $\mathbf{4 8} \mathrm{h}$ post-torsional larva of the gastropod molluse $\mathrm{Pa}$ tella. Mechanisms Dev.

Jenner RA. 1999. Metazoan phylogeny as a tool in evolutionary biology: current problems and discrepancies in application. Belgian J. Zool. 129: 245-262.

Jenner RA. 2000. Evolution of animal body plans: the role of metazoan phylogeny at the interface between pattern and process, Evol, Dev, 2: 208-221.

Jenner RA. 2001. Total evidence approach to bilaterian relationships compromised by uncritical recycling of poor morphological data. Systematic Biology 50: 730-742.

Jenner RA. 2002. Boolean logic and character state identity: pitfalls of character coding in metazoan cladistics. Contrib. Zool. 71: 67-91.

Jenner RA. in press. Unleashing the force of cladistics? Metazoan phylogenetics and hypothesis testing. Amer. Zool.

Jenner RA. in prep. Towards a phylogeny of the animal kingdom. I. An evaluation of morphological character support for alternative phylogenetic positions of the "acoelomate" worms: Platyhelminthes, Nemertea, and Gnathostomulida.

Jenner RA, Schram FR. 1999. The grand game of metazoan phylogeny: rules and strategies. Biol. Rev. 74: 121-142
Jenner RA, Schram FR. in press. Systematic Zoology: Invertebrates. In Encyclopedia of Life Support Systems. EOLSS Publishers Ltd. Co. UK.

Koenemann S, Schram FR. 2002. The limitations of ontogenetic data in phylogenetic analyses. Contrib. Zool. 71: 4765.

Schram FR, Jenner RA. 2001. The origin of Hexapoda: the crustacean perspective. In: Deuve T, ed. The Origin of Hexapoda. Ann. Soc. Entomol. France 37: 243-264.

Schram FR, Koenemann S. 2001. Developmental genetics and arthropod evolution: Part I, On legs. Evol. Dev, 3: 343-354.

Schram FR, Koenemann S. in press Developmental genetics and arthropod evolution: Part II, On body regions of Crustacea. Crustacean Issues.

Sluys R. 1999. Cocoon production, deposition, hatching, and embryonic development in the marine planarian Sabussowia dioica (Platyhelminthes, Trìcladida, Maricola). Invertebr. Reprod. Dev 35: 215-223.

van den Biggelaar JAM, Edinger-Gonzales E, Schram FR. 2002. The improbability of dorso-ventral axis inversion during animal evolution, as presumed by Geoffroy Saint Hilaire. Contrib. Zool 71: 29-36.

Wanninger A, Ruthensteiner B, Lobenwein S, Salvenmoser W, Dictus WJAD, Haszprunar G. 1999. Development of the musculature in the limpet Patella (Mollusca, Patellogastropoda). Dev. Genes Evol. 209: 226-238.

Wanninger A, Ruthensteiner B, Dietus WJAD, Haszprunar G. 1999. The development of the musculature in the limpet Patella with implications on its role in the process of ontogenetic torsion. Invertebr. Reprod. Dev. 36: 211-215.

Received: 11 June 2002 